\title{
RESOLVD: ICT services and energy storage for increasing renewable hosting capacity in LV distribution grids
}

\author{
Andreas Sumper, \\ Pau Plana-Olle, \\ Francesc Girbau-Llistuella, \\ Francisco Diaz-Gonzalez \\ Centre d'Innovació Tecnològica en \\ Convertidors Estàtics $i$ Accionaments \\ (CITCEA-UPC), \\ Departament d'Enginyeria Elèctrica, \\ Universitat Politècnica de Catalunya \\ ETS d'Enginyeria Industrial de \\ Barcelona, \\ Av. Diagonal, 647, P1. 2. 08028 \\ Barcelona, Spain. \\ andreas.sumper@upc.edu
}

\author{
Sanket Puranik \\ Smart Innovation Norway \\ Håkon Melbergs vei 16, 1783 Halden, \\ Norway \\ sanket.puranik@smartinnovationnorwa \\ y.com \\ Isidoros Kokos \\ Intracom Telecom \\ 19.7 km Markopoulou Ave., Peania, \\ GR 19002, Greece \\ isik@intracom-telecom.com
}

\author{
Joaquim Meléndez i Frigola \\ Dept. EEEA / IIiA \\ Universitat de Girona \\ c/Universitat de Girona, 6. 17003 \\ Girona, Spain \\ joaquim.melendez@udg.edu \\ Luisa Candido \\ Estabanell Distribució \\ c/ Rec, 28 - 08401 Granollers, Spain \\ lcandido@estabanell.cat
}

\begin{abstract}
This article presents the $\mathrm{H2020}$ project RESOLVD (Renewable Penetration Levered by Efficient Low Voltage Distribution Grids). The purpose of this project is to improve the efficiency of distribution networks at the same time while increasing the hosting capacity of distributed renewable generation by introducing flexibility by storage management and control in the low voltage grid. This paper collects the most significant insights from the RESOLVD project by summarizing the needs and expectations of the involved stakeholders to give a complete understanding of the context of the project. Subsequently, the RESOLVD technology is presented, both the software as well as the hardware solutions. Next, the existing and upcoming regulation initiatives are presented and analyzed. Finally, the conclusions of the project and recommendations to standardizing and regulatory bodies are provided.
\end{abstract}

Keywords-Smart Grid, ICT, Clean Energy Package, Regulation and Standardization

\section{INTRODUCTION}

RESOLVD H2020 is a European Union-funded research and innovation action consisting of a consortium of seven partners from Spain, Greece, Austria, Norway and Slovenia coordinated by the Universitat de Girona [1]. The main objective of RESOLVD is to improve the efficiency of distribution networks and to increase the hosting capacity in a context of highly distributed renewable generation scenario by introducing flexibility and control in the low voltage grid. The main points of research and innovation of this project are [2]:

- a power electronics device (PED) with integrated storage management capabilities based on innovative techniques

- cost-effective phasor measurement units (PMUs) for enhanced observability of low voltage grids

- short-term forecasting algorithms predicting demand and local renewable generation

- improved observability and improved energy control, through power electronics,
- an improved grid monitoring of the low voltage with (local) wide area monitoring system (WAMS) capabilities. It enables the detection and forecast of critical episodes and the scheduling of optimal grid configuration and energy management through heterogeneous storage elements.

These developed RESOLVD tools are integrated with the distribution operator legacy systems (SCADA, AMI, MDMS, etc.) in secure and safe conditions. This system is being validated in the pilot grid owned by the project partner Estabanell Distribució, Spain, until the end of the project in 2021. The pilot grid consists of two interconnected secondary low voltage substations with prosumers having photovoltaic installations.

\section{NEEDS AND EXPECTATIONS FROM INVOLVED SECTORS}

\section{A. Stakeholder identification}

Distribution networks were initially designed to transport electricity unidirectionally, from generation (which can be scheduled with high predictability) through the transmission grid to "passive" customers. Introduction of distributed generation (DG) in the distribution network has led to a significant impact on the power flow and consequently, in the voltage (quality of supply) and current (congestion) conditions, which affects various parts of the utility/consumer equipment and protection devices. To cope with challenges arising from DG, new solutions are being developed under the umbrella of smart grid technologies.

DG, together with distributed energy resources like electric vehicles (EV) and energy storage technologies have led to the emergence of new stakeholders in the energy domain, which can also be called new market actors. Prosumers, aggregators, and charge point operators are few such new stakeholders.

Energy transition has its challenges and is redefining the roles of different stakeholders. To address the challenges which come with the energy transition, needs and expectations of various stakeholders have to be reassessed. This shall 
provide critical insights into what technologies would be required in the market in the near future. Table I is listing the identified stakeholders of the solution addressed in the RESOLVD project. More detailed information on the stakeholder analysis can be found in $[3,4]$.

TABLE I. LIST OF IDENTIFIED STAKEHOLDERS AND THEIR NEEDS

\begin{tabular}{|c|c|}
\hline Stakeholder & Needs \\
\hline Prosumers & $\begin{array}{l}\text { Higher integration of self-generated } \\
\text { electricity } \\
\text { Better information for making decisions } \\
\text { on investments in renewables } \\
\text { - } \quad \text { Lower electricity price/grid tariff }\end{array}$ \\
\hline $\begin{array}{l}\text { Distributions } \\
\text { system operators } \\
\text { (DSO) }\end{array}$ & $\begin{array}{ll}\text { - } & \text { High-resolution grid monitoring } \\
\text { - } & \text { Better grid management for improved } \\
& \text { reliability and power quality } \\
\text { - } & \text { Reducing losses } \\
\text { - } & \text { Delaying upgrade investments } \\
\text { - } & \text { Improved cybersecurity measures }\end{array}$ \\
\hline $\begin{array}{l}\text { Balancing } \\
\text { Responsible } \\
\text { Parties (BRPs) }\end{array}$ & - $\quad$ Minimize imbalances \\
\hline Aggregators & $\begin{array}{ll}\text { - } & \text { Capitalize on flexibility } \\
\text { - } & \text { Better demand and generation forecasting } \\
\text { - } & \text { New markets and market actors to } \\
& \text { provide products and services. } \\
\end{array}$ \\
\hline Retailers & $\begin{array}{l}\text { Better predictions for making low-risk } \\
\text { trading decisions }\end{array}$ \\
\hline $\begin{array}{l}\text { Distributed } \\
\text { generation owners }\end{array}$ & $\begin{array}{l}\text { Improved integration of local energy } \\
\text { production to increase profitability }\end{array}$ \\
\hline $\begin{array}{l}\text { Energy } \\
\text { communities }\end{array}$ & $\begin{array}{ll}\text { - } & \text { Increased consumption from local energy } \\
\text { - } & \text { Imprources } \\
\text { - } & \text { Economic benefits from flexibility } \\
\text { - } & \text { Possibly lower electricity price/grid tariff }\end{array}$ \\
\hline $\begin{array}{l}\text { Building } \\
\text { operators, } \\
\text { microgrid } \\
\text { operators, } \\
\text { industries }\end{array}$ & $\begin{array}{l}\text { Increased attractiveness through green } \\
\text { profiling and innovative energy solutions } \\
\text { - } \\
\text { Possibility to trade energy flexibility } \\
\text { assets } \\
\text { Better information for making decisions } \\
\text { on investments in renewables } \\
\text { Efficient management of facilities - } \\
\text { reduced electricity costs }\end{array}$ \\
\hline $\begin{array}{l}\text { Charge point } \\
\text { operators } / \text { Charge } \\
\text { point } \\
(\mathrm{CPO})\end{array}$ & 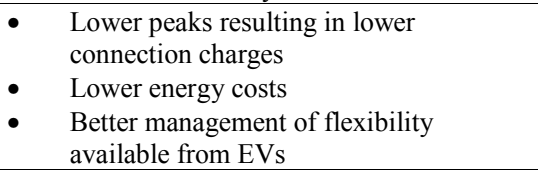 \\
\hline $\begin{array}{l}\text { Suppliers } \\
\text { (hardware, } \\
\text { software, ICT } \\
\text { infrastructures) }\end{array}$ & $\begin{array}{l}\text { - Capitalize on new technologies related to } \\
\text { storage, and ICT infrastructures } \\
\text { - Gain a competitive edge in the market } \\
\text { with novel technologies in their portfolio }\end{array}$ \\
\hline $\begin{array}{l}\text { Battery } \\
\text { manufacturers/sup } \\
\text { pliers }\end{array}$ & - Increase battery sales \\
\hline $\begin{array}{l}\text { Transmission } \\
\text { system operators } \\
\text { (TSO) }\end{array}$ & $\begin{array}{l}\text { - } \quad \text { Better grid management /reliability } \\
\text { - } \quad \text { Receive balancing services at lower cost }\end{array}$ \\
\hline
\end{tabular}

\section{B. Stakeholder interviews}

To further consolidate findings from stakeholder analysis, face-to-face and telephonic interviews have been conducted with industry experts and members from GEODE association. GEODE members comprise of independent distribution companies of gas and electricity representing more than 1200 companies in 15 countries all ever Europe, both private and public owned. Together they supply a population of approximately 100 million people in the EU and represent influential voices of medium and small DSOs across Europe [5]. GEODE was targeted for interviews because DSOs are prime beneficiaries of RESOLVD project. GEODE was targeted for interviews because DSOs are prime beneficiaries of RESOLVD project. Interviews aimed to understand the viewpoint from the influential stakeholders about issues addressed by RESOLVD and market perspectives on the project outcomes.

Interview questions were framed to collect viewpoints of industry experts on next-generation technologies (both hardware and software), which would be needed for efficient operations of future smart grid. The scope of these questions was limited to improving the hosting capacity of the distribution grid. The questions focus on three aspects: (1) current and future challenges of DSOs under DG, (2) identification and validation of value propositions regarding advanced distribution management software tools, higher distribution grid visibility, novel power electronics for multiple storage management, and (3) how experts perceive the role of DSOs in future smart grids.

In total, 7 iterviews were conducted, which consisted of high-level industry experts from different stakeholder classes. Interviewees represented DSOs, regulatory bodies, and storage solution providers. Norway, Finland, Austria, and Germany were the geographic locations where these stakeholders are located.

\section{Key outcomes of the interviews}

The following list summarizes the conclusions has been drawn from the interview [4]:

- A general agreement is that solutions to manage LV grid actively are required, but when such solutions are needed depends upon DG penetration in a country as well as how much investments have already been done on grid upgrades.

- Next, investments are expected to happen at medium voltage (MV) level. In general, a trend is being observed in increased costs associated with electricity distribution and transmission. Rural areas where grid connections are weaker would require smart grid technologies first.

- Capital expenditure friendly regulation, as opposed to operational expenditure friendly one, is a significant barrier for investment in smart technologies. To support innovations which enhances operational efficiency in LV grid regulations need to be adjusted accordingly.

- Flexibility services are effective in managing the grid. However, incentives are required which shall allow stakeholders to capitalize on such services. Further market mechanisms are required to facilitate the exchange of flexibility services between various market participants.

- Experts foresee that regulations will not allow DSO to own storage and in general, there is consensus that DSO should procure services from storage through a market mechanism.

- It is expected that the battery solution will become a very lucrative option in the next 2-5 years. Need for advanced grid operation services like anti-islanding and self-healing will arise after five years. 
- Phasor measurement units market demand is expected to arise in the long term (beyond five years) and will depend on economic feasibility rather than technical.

- Reactive power management is a relevant issue faced by DSO across different countries, and interviewees agree that this can be solved through power electronics and battery technologies.

- When asked about business models for smart technologies, including storage, all the stakeholders had different views. Still, they agreed that regulation should play a vital role in deciding what business model will work.

- The role of the DSO will be similar as it is today, but it has to play a more active role in future. Here again, regulations have to be clear on what are market boundaries for DSO business.

- There is no clarity at the moment if DSO should become a local market facilitator for flexibility.

A general observation is that for investing in new technologies and changing business models, stakeholders are waiting for regulators to lead the way. Different stakeholders are testing new technologies at an experimental level to understand its importance and already have an opinion on what technologies might be successful. However, when it comes to business models, there are no strong opinions.

\section{THE RESOLVD SOLUTION}

The RESOLVD analyzed a set of use cases (Table II) that can potentially improve the hosting capacity of low voltage grids [6].

TABLE II. LIST OF IDENTIFIED HIGH-LEVEL USE CASES (HLUCS)

\begin{tabular}{|l|}
\hline \multicolumn{1}{|c|}{ HLUCs } \\
\hline $\begin{array}{l}\text { HLUC01: Prevention of congestion and over/under voltage issues } \\
\text { through local storage utilization and grid reconfig. }\end{array}$ \\
\hline $\begin{array}{l}\text { HLUC02: Voltage control through reactive power injection or } \\
\text { consumption. }\end{array}$ \\
\hline $\begin{array}{l}\text { HLUC03: Improving power quality and reducing losses through } \\
\text { power electronics. }\end{array}$ \\
\hline $\begin{array}{l}\text { HLUC04: Reduction of power losses through local storage } \\
\text { utilization. }\end{array}$ \\
\hline HLUC05: Self-healing after a fault. \\
\hline HLUC06: Power management in intentional controlled island mode. \\
\hline $\begin{array}{l}\text { HLUC07: Detection and interruption of unintentional uncontrolled } \\
\text { islanding. }\end{array}$ \\
\hline
\end{tabular}

\section{A. The platform as a software solution}

RESOLVD platform is a software solution to integrate the advanced active distribution grid management functionalities and monitoring of the low voltage grid developed in the project [7]. The platform is comprised of the following set of tools:

- Enterprise Service Bus (ESB), offering transparent integration with:

○ Legacy systems of the DSO (i.e. MDMS, SCADA, GIS),

- Power Electronic Devices (PEDs),

○ External systems (i.e. Weather services),
○ Wide Area Monitoring System (WAMS);

- Data Management System, offering storage of data from heterogeneous data sources and different data types providing data validation and homogenization as well as guaranteeing accessibility with specific QoS characteristics;

- Supervision and Analytics Services, offering grid monitoring and optimal operation abilities, through advanced forecasting, grid event detection and optimization of grid asset dispatch, as a service;

- Operation Applications, providing the end-user interface, for visualizing the status of the grid, the parameterization of the different business flows of the advanced grid functions, as well as for analysis of the impact of asset dispatch in the grid's operation.

A high-level architecture of the solution is presented in Fig. 1, detailing the interaction of the above tools with their ecosystem.

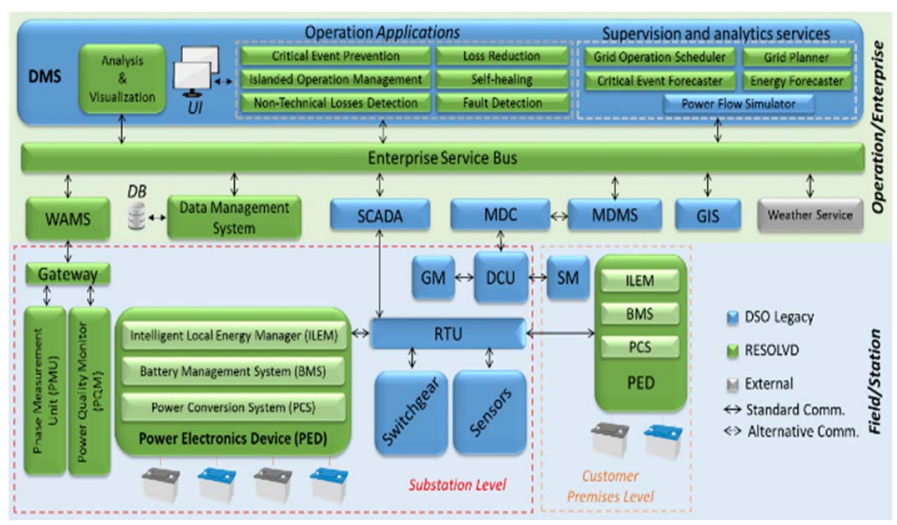

Fig. 1. RESOLVD Architecture: Component view

\section{B. The PED as a hardware solution}

The Power Electronics Device is developed in the project and is equipped with local energy storage to provide flexibility to low voltage grids. As an energy storage system, it can enhance the operation and power quality of low voltage grids by, for instance, contributing to the supply security for customers in case of grid eventualities; controlling active and reactive power flows to the network following economic and / or technical criteria, and compensating current harmonics through cables affecting customers. Furthermore, an energy storage solution in the distribution grids can also enhance the hosting of renewables, reduce the impact of electric vehicles, manage the grid assets congestion, and be an energy back-up for utilities and communities.

The PED is composed of two main subsystems, which are framed into the power (hardware) plane and the management plane. The components included within the hardware plane are those exchanging power with the external network the PED is connected to. So, in this regard, there are the Power Conversion System (PCS- Fig. 2) and batteries. The power plane of the PCS is modular to integrate different batteries of diverse characteristics. In detail, the PCS architecture for modular and hybrid energy storage consists of front-end inverter modules together with parallel dual active bridge modules. This power architecture offers excellent reliability, efficiency, compactness and behavior under grid faults. Besides, it provides excellent flexibility while integrating different batteries of different characteristics [8,9]. 
Therefore, the electrical specifications of the PED are summarized in Table III.

TABLE III. ELECTRICAL SPECIFICATION OF PED

\begin{tabular}{|c|c|c|}
\hline \multicolumn{3}{|c|}{ Electrical specs } \\
\hline Inverter stage topology & \multicolumn{2}{|c|}{ 4-wires 3-phase bridge split capacitor } \\
\hline AC rated power & \multicolumn{2}{|c|}{$75 \mathrm{kVA}$} \\
\hline $\begin{array}{c}\text { Rated AC voltage (phase } \\
\text { to neutral) }\end{array}$ & \multicolumn{2}{|c|}{$400 \mathrm{~V}$ (230 V compatible) } \\
\hline AC Voltage range & \multicolumn{2}{|c|}{$85 \%-110 \%$ (according to EN 50438) } \\
\hline AC Frequency & \multicolumn{2}{|c|}{$50 \mathrm{~Hz}(60 \mathrm{~Hz}$ compatible $)$} \\
\hline AC Rated current & \multicolumn{2}{|c|}{$108.6 \mathrm{~A}$} \\
\hline DC/DC stage topology & $\begin{array}{l}\text { DAB } 1 \text { (galvanic } \\
\text { isolation) }\end{array}$ & $\begin{array}{l}\text { DAB } 2 \text { (galvanic } \\
\text { isolation) }\end{array}$ \\
\hline DC rated power & $20 \mathrm{~kW}$ & $20 \mathrm{~kW}$ \\
\hline DC rated voltage & $345 \mathrm{~V}$ & $240 \mathrm{~V}$ \\
\hline $\begin{array}{c}D C \text { voltage range (at } \\
\text { rated power) }\end{array}$ & $315 \mathrm{~V}-385 \mathrm{~V}$ & $200 \mathrm{~V}-270 \mathrm{~V}$ \\
\hline DC rated current & $63.5 \mathrm{~A}$ & $100 \mathrm{~A}$ \\
\hline
\end{tabular}

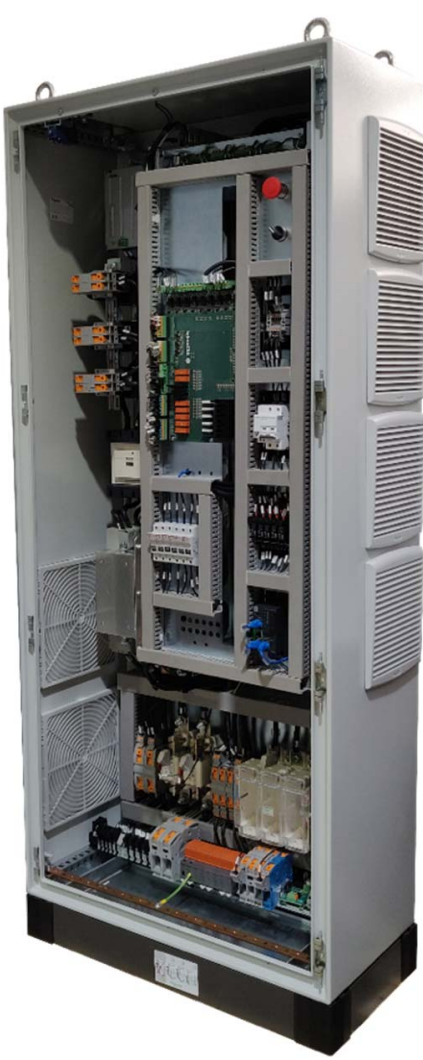

Fig. 2. PED cabinet without the front door

\section{REGULATION FRAMEWORK}

In November 2016 The Clean Energy Package (CEP) was published as a "recast" of the Third Energy Package (2009), containing a set of regulations and directives to continue the energy transition within the Energy Union.

Within the CEP regulations and directives, the e-Directive (EC 2019/944; [10]) and the e-Regulation (EC 2019/943; [11]) are the ones referring to the electric sector. Their subject matter and scope is centered on setting "the basis for an efficient achievement of the objectives of the Energy Union and in particular the climate and energy framework for 2030 (e-Regulation), via the creation of common rules for all the assets connected to the power system, with a view to creating truly integrated, competitive, consumer-centered, flexible, fair and transparent electricity markets in the Union". Besides, they also focus on establishing models for system operators to enhance cooperation and set egalitarian regulations for crossborder exchanges.

Creating energy markets to support and ease the transition towards a distributed and RES-based power system is one crucial objective of the e-Directive and e-Regulation. In this sense, the CEP sees flexibility markets as vital to promote the widespread of new agents and technologies in the energy sector [12]. In the e-Directive, the role of aggregators and Energy Storage Systems (ESSs), is enhanced. They are mentioned continuously as important agents and technologies, which would benefit from tailor-made regulations. Also, the e-Regulation targets the same objective stating "safe and sustainable generation, energy storage and demand response shall participate on equal footing in the market [...]".

On flexibility, the e-Regulation sets its scope on the aggregator actor as a way to promote smaller loads active participation in the power system, while at the same time promotes the long-term investments that will still be important for the development of the markets. This change of mindset can also be observed in e-Directive Art. 8 where member states are required to consider alternatives such as demand response and energy storage before authorizing the construction of new capacity.

The statement "Market participants engaged in the aggregation are likely to play an important role as intermediaries between customer groups and the market" is extracted from the e-Directive provision (39). In this sense, the customers right to freely purchase aggregation services is defined on e-Directive Art. 13. Something similar happens with balancing market participation of aggregators which should not be hindered, and demand response through aggregation, which is promoted in the CEP. Overall, the CEP defines a framework stating that any consent of other market participants should not hinder aggregators from entering electricity markets.

Article 32 (2) of the e-Directive sets the basis of flexibility markets for local congestion management, an emerging market for distribution grid ancillary services, where local aggregators and ESSs can become relevant market participants.

Focusing on ESSs, the CEP tackles some of the concerns identified by stakeholders and researchers to previous directives. The official definition of Energy Storage from a technology-neutral approach (e-Directive: Art. 2 (59) is one of the crucial contributions of the CEP. It also promotes the use of energy storage within DSO network planning as an alternative to system expansion in e-Directive Art. 32 (3). This kind of considerations, show the CEP vision of ESSs and other technologies to become crucial in the power system, for instance providing stability and investment deferral.

The CEP also addresses the willingness of the EU to unbundle the electricity sector. In Article 36 of the eRegulation, it is stated that "Distribution system operators shall not own, develop, manage or operate energy storage facilities" to provide services that can be obtained via existing electricity markets. This unbundling of the power system aims to provide a level playing field for all participants, which should lead to a fairer electricity system.

From the prosumer viewpoint, e-Directive Art. 15 (5) aims to solve one crucial issue regarding ESSs and their ability to 
act as a generator and as a load. Point (b) of the article determines that member states shall ensure active customers owning ESSs that would not be subject to any double taxation. Furthermore, point (d) allows the same storage facility owned by an active customer to provide several services simultaneously, if technically feasible. Such definitions, for instance (d), can become a crucial driver for the spread of ESSs and other new technologies, because specific definitions remove incertitude and allow to take advantage of ESSs full potential.

However, while the CEP directives and regulations are aiming to better integrate ESSs on the power grid, the current generation [13] and Demand Connection [14] Grid Codes, exclude ESSs from their scope and application on Article 3, with the exception of Pumped Hydroelectric Energy Storage (PHES).

To conclude, the CEP e-Regulation Art. 59 1(e) sets as a future outcome the development of specific network codes for energy storage and aggregation. These new network codes could suppose an essential driver for energy storage and aggregation, as already have been the Electricity Balancing guidelines for balancing markets throughout Europe.

\section{CONCLUSIONS FROM THE RESOLVD PROJECT FOR STANDARDIZATION AND REGULATION BODIES}

\section{A. Common Information Model}

The Common Information Model (CIM) [15] can be considered as one of the core standards for the transition to smart grids. This model was initially developed for the transmission grid but later expanded by the description of the distribution grid as well as energy markets related interactions.

Based on the CIM family of standards, a Canonical Data Model (CDM) was designed for the information flowing from/to the RESOLVD Platform in the context of the control center. More specifically, the following standards were considered during the data modelling process:

- $\quad$ IEC61968 series [16], which deals with information exchanges in electrical distribution systems and was developed by IEC Technical Committee 57,

- CGMES [17] (v2.4.15), which was developed by ENTSO-E as a European profile ${ }^{1}$ of CIM, whilst it was adopted by the IEC as IEC CGMES Technical Specifications (IEC TS 61970-600-1:2017 and IEC TS 61970-600-2:20).

To address the specificities of the project, custom schemas were created as subsets of the above profiles or new data schemas were created from existing CIM classes, and in some occasions by extending existing classes of the standard data model. The modelling of the information involved the following information objects:

- Measurements: Inspired by IEC 61968-9 [18] profile;

- Forecasts: The above measurement model with some extensions was used to handle energy and critical event forecasting provided by the Energy Forecaster;
- Grid Model: Created based on CGMES "Equipment" (EQ) profile with some modification to model the PED. Data from the GIS were converted to this data model;

- Grid Configuration/Status: Utilizes the CGMES "Steady State Hypothesis" (SSH), "Topology" (TP) and "State Variables" (SV) profiles for modelling the status of the grid and the PED assets, tackling as well the communications with the Power Flow Simulator (PFS);

- Grid Schedule: Initiates from the "Wires" package and models the schedules of the Switchgear and the PED, also utilizing classes from "Core" and "LoadModel" packages. It mostly focuses on communication with the Supervisory Control and Data Acquisition system (SCADA) and the Grid Operation Scheduler (GOS);

- Faults: Based on the "Faults" package as well as "Core" can "Common", a schema was identified for modelling the faults occurring in the grid, identified by Fault Detection Application.

CIM provided a useful guideline towards designing an interoperable solution, even though there was a significant overhead in the initial phases of the design, given the model covers a vast domain, is fractioned in many packages and there are hundreds of classes and several relationships among them. Nevertheless, the model provides great flexibility for designing domain-related information. For instance, there were several ways to model the PED in the grid model. On the other hand, this may create confusion; hence, proper guidance is required on applying the standards in the modelling phase. Following this experience with this standard series, what was also identified, was an absence of modelling of energy forecast information object, which is trivial in applications designed in the context of smart grids.

\section{B. Regulation}

As part of the Clean Energy Package, both e-Regulation and e-Directive were approved in 2019, as a framework for the transition towards cleaner and more sustainable energy. The Member States are now called to implement and transpose into national laws this framework and to ensure consequently the energy industry a stable legal environment. From the energy industry perspective, they are also forced to adapt themselves to this new regulation framework, which can bring challenges as well as opportunities.

Art. 32 on Incentives for the use of flexibility in distribution networks of the e-Directive is establishing that distribution system operators should procure services from providers with transparent non-discriminatory and marketbased procedures. However, such market-based procedures are not further defined. No clarification on centralized or peerto-peer approach, size, nor timeframes are given. Here market design will be fundamental to establish rules where investment in flexibility assets operating on such markets need a stable framework to invest.

Network codes are foreseen in e-Regulation (Art.59), and these codes need to be developed and adopted to national law. It is interesting to see the conclusion of GC0096 [19] on

\footnotetext{
${ }^{1}$ A profile is a subset model of the full CIM model which can act as a selfcontained model and focuses on a specific application domain.
} 
Energy Storage (UK - Grid Code modification report), highlighting that the most crucial change to include energy storage in network codes is the proper definition of its capabilities and configurations, more than technical requirements. Therefore, from this perspective, the changes on the network codes regarding including storage or other services would not suppose a significant intervention. The main issue lies in how novel assets like storage may participate in market-based procedures.

Traditionally, DSOs are making their investment decisions based on the investment for novel assets following national regulation that are using schemes to reward the Capital Expenditure (CAPEX) of those investments. With the establishment of market-based procedures to use flexibility in distribution networks, it is needed to explore new hybrid approaches, also taking into account the Operational Expenditure (OPEX).

\section{ACKNOWLEDGMENT}

This work has been developed under the European project RESOLVD of the Horizon 2020 research and innovation program (topic LCE-01-2016-2017) and grant agreement $\mathrm{Nr}$. 773715. All information in this publication reflects only the authors' view. Authors signs on behalf of the partners' team. RESOLVD project would like to thank all the interviewees, especially GEODE and its members to support the work done in the project by accepting interviews and providing their valuable insights on the topic.

\section{REFERENCES}

[1] RESOLVD - Web Page. https://resolvd.eu/ [Accessed: 29/2/2020]

[2] J. Melendez Frigola, I. Kokos, H. Tuiskula, S. Marksteiner, A. Sumper, R. Gallart, M. Smolnikar, F. Torrent Fontbona; "RESOLVD Renewable penetration levered by efficient Low Voltage Distribution grids. Specifications and use case analysis" Presented at CIRED 2019, [Online]. Available: https://www.ciredrepository.org/handle/20.500.12455/661

[3] RESOLVD, "Draft D6.1 - Stakeholders, actors and roles," 2018.

[4] RESOLVD, "D6.2 - Stakeholders, actors and roles, Final Version," 2018
[5] GEODE, “Geode." [Online]. Available: http://www.geodeeu.org/home/about-u. [Accessed: 20/2/2019].

[6] RESOLVD, "D1.1 - Use Case Definition," 2018.

[7] RESOLVD, "D.4.1 - Detailed description of the platform," 2018.

[8] RESOLVD, "D.2.1 - Power electronics device design specifications and models for the architectures," 2018.

[9] F. Díaz-González, D. Heredero-Peris, M. Pagès-Giménez, E. PrietoAraujo and A. Sumper, "A Comparison of Power Conversion Systems for Modular Battery-Based Energy Storage Systems," in IEEE Access, vol. 8, pp. 29557-29574, 2020, doi: 10.1109/ACCESS.2020.2972412.

[10] European Commission, "Directive (EU) 2019/944 of the European Parliament and of the Council of 5 June 2019 on common rules for the internal market for electricity and amending Directive 2012/27/eu," Official Journal of the European Union, vol. 62, no. L 158, pp.125, 2019

[11] European Commission, "Regulation (EU) 2019/943 of 5 June 2019 on the internal market for electricity," Official Journal of the European Union, vol. 62, no. L 158, pp. 54-124, 2019.

[12] Z. Xu, "The electricity market design for decentralized flexibility sources," Oxford, United Kingdom, Jul. 2019.

[13] European Commission;, "Commission Regulation (EU) 2016/631 Establishing a Network Code on Requirements for Grid Connection of Generators," Official Journal European Union, no. 14, 2016, p. 68, 2016.

[14] European Commission, "Commission Regulation (EU) 2016/1388 of 17 August 2016 establishing a Network Code on Demand Connection," Official Journal European Union, no. L 223, pp. 10-54, 2016.

[15] A. McMorran, "Common Information Model Primer, Third Edition," 2015.

[16] "IEC - Smart grid > IEC Standards." [Online]. Available: https://www.iec.ch/smartgrid/standards/. [Accessed: 24-Feb-2020].

[17] "Common Grid Model Exchange Standard (CGMES) Library." [Online]. Available: https://www.entsoe.eu/digital/cim/cim-for-gridmodels-exchange/. [Accessed: 24-Feb-2020].

[18] "IEC 61968-9:2013 Application integration at electric utilities - System interfaces for distribution management - Part 9: Interfaces for meter reading and control.".

[19] A. Johnson,"Gridcode modification GC0096: Energy storage - Final modification report," National Grid System Operator, Tech. Rep., dec 2019. 